\title{
REVIEW ON RASPBERRY Pi 3b+ AND ITS SCOPE
}

\author{
Omkar Nath \\ Department of Automobile \\ Rustamji Institute of Technology, Gwalior, Madhaya Pradesh, India
}

\begin{abstract}
The Raspberry pi $3 \mathrm{~b}+$ is a small size Single Board Computer (SCB) having almost the size of a creditcard. It uses ARM (Advance RISE Machine) with clock speed 1.4 GHz 64Bit quad-core processor. Now a days it became very popular in the field of IOT (Internet of Thing), Data acquisition, Real time sensor monitoring, robotics, Home automation because of its low cost, small size and great performance. This paper describes the Raspberry pi technology, design of its components, scope and various projects on Raspberry $\mathrm{Pi} 3 \mathrm{~b}+$
\end{abstract}

Keywords - Raspberry pi 3b+, Single Board Computer (SCB), ARM, IOT, Data Acquisition.

\section{INTRODUCTION}

Today the technology is heading toward automaton, IOT, Real time sensors monitoring, Data Acquisition, Robotics and Raspberry pi is a perfect device which is capable of doing all these things very efficiently.

For many years the work was done on Arduino but the difference is Arduino is a micro-controller and Raspberry pi is a microprocessor it can process the data very efficiently with its $1.4 \mathrm{GHz}, 64$ Bit Quad-core ARM processor. Raspberry pi is based on Linux and now windows Operating system is also available which is windows 10 IOT core various versions of operating system are Raspbian, Ubuntu Mate, Ubuntu core, OSMC, PiNet, RISC os these can be downloaded from Raspberry Pi forum .It supports python as its main programming language and it also supports BASIC,C,C++,JAVA, Perl and Ruby.[1]

\section{SPECIFICATION OF RASPBERRY Pi 3b+}

- Broadcom BCM2837B0, Cortex-A53 (ARM) 64-bit $\mathrm{SOC}$

- $\quad 1.4 \mathrm{GHz}$ 64-BIT quad-core CPU

- 1 GB RAM

- $\quad$ USB $2.0=4$ ports

- Video: VideoCore IV 3D. Full-size HDMI

- WIFI: Dual-band 802.11ac wireless LAN (2.4GHz and $5 \mathrm{GHz}$ ) and Bluetooth 4.2
- Ethernet: Gigabit Ethernet over USB 2.0 (max 300 Mbps). Power-over-Ethernet support (with separate PoE HAT). Improved PXE network and USB massstorage booting.

- Camera Serial Interface (CSI), Display Serial Interface (DSI)

- 40-GPIO (General purpose input/output) pins

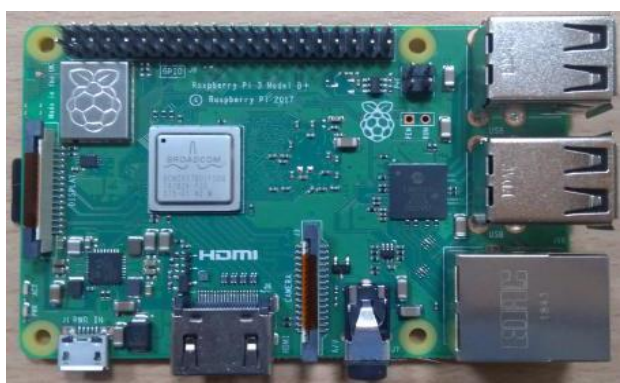

Fig1: Raspberry pi 3b+

III. GPIO PINS

Raspberry Pi uses 40 GPIO pins it is use to take input and give output, in raspberry pi all the GPIO pins are digital pins they Cannot read Analog input or output so to connect the raspberry Pi with Analog sensor external ADC (Analog to Digital Converter) is required.

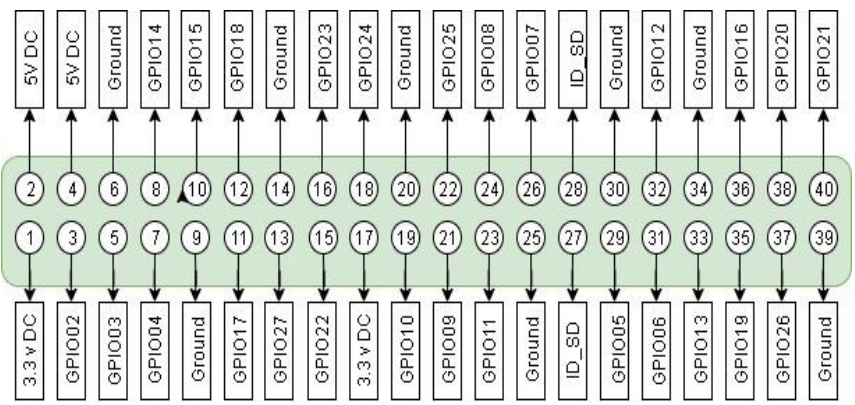

Fig2: GPIO pins

MCP3008:The MCP3008 is a low cost 8-channel 10-bit analog to digital converter and with 8 channels it can read quite a few analog signals from the Raspberry Pi. 


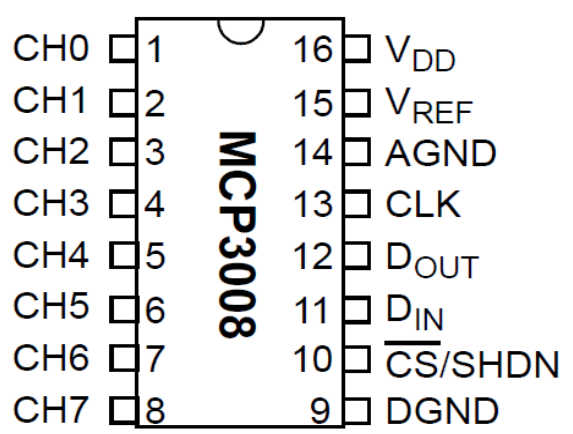

Fig 3: Pin-out of MCP3008

\section{BOOTING OF RASPBERRY pi}

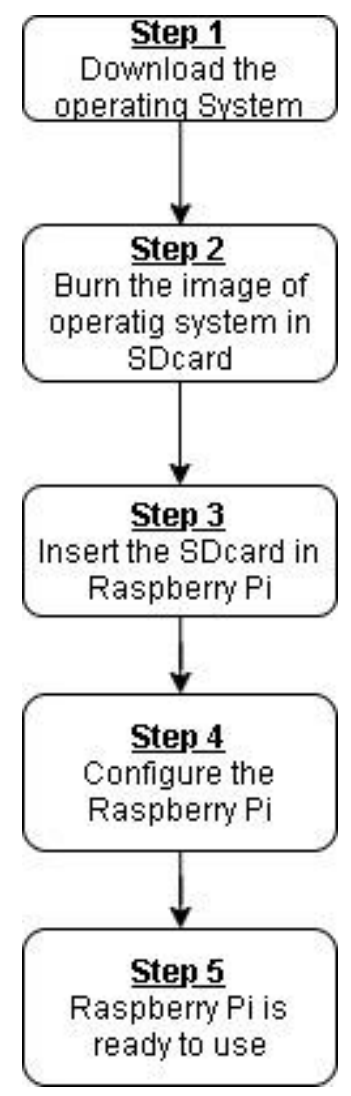

Fig 4: Flow chart of Booting Process

\section{VARIOUS PROJECT ON RASPBERRY pi}

- Design and implementation of Green Ecological supervision using Raspberry pi.[2]

- Wheelchair Controlled by Eye Movement Using Raspberry pi for ALS Patients.[3]
- Robotic Hand- Eye Using Machine Learning and Raspberry pi.[4]

- Intelligent system for monitoring vital signs at patients' home [5]

- Raspberry pi based interactive home automation through E-mail[6]

- Raspberry Pi as a Sensor Web node for home automation.[7]

- $\quad$ An IoT based patient monitoring system using raspberry Pi[8]

- Low cost real-time system monitoring using Raspberry Pi[9]

- An Internet of things approach for motion detection using Raspberry Pi[10]

- Access Control of Door and Home Security by Raspberry Pi Through Internet. [11]

- IoT based biometrics implementation on Raspberry Pi[12]

There are lots of projects and intelligent system can be made with the use of Raspberry pi, It can be used for making Smart cities and smart devices etc. its scope is very big in future.

\section{CONCLUSIONS}

The Raspberry Pi is small size single board computer which can be use in various fields such as Robotics, IOT, Medicine, sensors monitoring, Data Acquisition system and many others, The price of Raspberry pi is low and due to its processing speed Pi based systems can be easily develop and also it is very helpful for making smart cities, smart home and smart systems. Lastly it can be said that Raspberry pi is a very efficient single board computer and it will play a significant role in making a smart world.

\section{REFERENCES}

[1] Pritish Sachdeva and Shutik Katchii (2014) A Review Paper on Rapberry pi, International Journal of current Engineering and Technology, Vol4, NO.6

[2] Madhuri Gummineni, Shilpa Narlagiri, Sudha Rani Chidurala (2020), Design and Implementation of Green Ecological Supervision Using Raspberry $\mathrm{Pi}$, Advances in Intelligent Systems and Computing, 1014, pp. 238-245.

[3] Buele, J., Varela-Aldás, J., Salazar, F.W., Soria, A., Andaluz, V.H. (2020) Wheelchair Controlled by Eye Movement Using Raspberry Pi for ALS Patients, Advances in Intelligent Systems and Computing, 1099, pp. 124-136

[4] Jariwala, S., Chaubal, O., Singh, R., Bakade, K(2020). Robotic Hand-Eye System Using Machine Learning Advances in Intelligent Systems and Computing, 1039, pp. 707-715. 
[5] Fuior, R., Andriţoi, D., Luca, C., Corciovă, C.

Intelligent system for monitoring vital signs at patient's home (2019) IFMBE Proceedings, 77, pp. 439-445. Volume 77, 2020, Pages 439-4454th International Conference on

Nanotechnologies and Biomedical Engineering, ICNBME 2019; Chisinau; Moldova; 18 September 2019 through 21 September 2019; Code 232319

[6] Jain, S., Vaibhav, A., \& Goyal, L. (2014, February). Raspberry $\mathrm{Pi}$ based interactive home automation system through E-mail. In 2014 International Conference on Reliability Optimization and Information Technology (ICROIT) (pp. 277-280). IEEE.

[7] Vujović, V., \& Maksimović, M. (2015). Raspberry Pi as a Sensor Web node for home automation. Computers \& Electrical Engineering, 44, 153-171.

[8] Kumar, R., \& Rajasekaran, M. P. (2016, January). An IoT based patient monitoring system using raspberry Pi. In 2016 International Conference on Computing Technologies and Intelligent Data Engineering (ICCTIDE'16) (pp. 1-4). IEEE.

[9] Nguyen, H. Q., Loan, T. T. K., Mao, B. D., \& Huh, E. N. (2015, July). Low cost real-time system monitoring using Raspberry Pi. In 2015 Seventh International Conference on Ubiquitous and Future Networks (pp. 857-859). IEEE.

[10] Ansari, A. N., Sedky, M., Sharma, N., \& Tyagi, A. (2015, January). An Internet of things approach for motion detection using Raspberry Pi. In Proceedings of 2015 International Conference on Intelligent Computing and Internet of Things (pp. 131-134). IEEE.

[11] Chowdhury, M. N., Nooman, M. S., \& Sarker, S. (2013). Access Control of Door and Home Security by Raspberry Pi Through Internet. Int. J. Sci. Eng. Res, 4(1), 550558.

[12] Shah, D., \& Haradi, V. (2016). IoT based biometrics implementation on Raspberry Pi. Procedia Computer Science, 79, 328-336. 